Asian-Australasian Journal of

Food Safety and Security

ISSN 2523-1073 (Print) 2523-2983(Online)

www.ebupress.com/journal/aajfss

\title{
Article \\ Thin layer chromatographic detection of enrofloxacin antibiotic residues in poultry tissues
}

\author{
Md. Mominul Islam Bhuiyan, Md. Shafiqul Islam, Md. Rakibul Hasan and Kazi Rafiqul Islam
}

Department of Pharmacology, Faculty of Veterinary Science, Bangladesh Agricultural University, Mymensingh-2202, Bangladesh

*Corresponding author: Dr. Md. Shafiqul Islam, Professor, Department of Pharmacology, Bangladesh Agricultural University, Mymensingh, Bangladesh. E-mail: shafiqpharma@yahoo.co.uk

Received: 24 March 2021/Accepted: 20 May 2021/ Published: 31 May 2021

\begin{abstract}
Antibiotic residues remain in edible portion of meat animals that have been treated with antibiotics. The aim of this study was to detect enrofloxacin residue after discriminate and indiscriminate administration and investigate the effect of enrofloxacin in growth of poultry. 18 broilers DOC (Cobb-500) were collected \& reared up to 31 days. On day 16, they were randomly divided into 3 groups, namely Group-A (Control group), Group$\mathrm{B}$ (Discriminate group) and Group-C (Indiscriminate group). Each group contains 6 birds. The discriminate and indiscriminate groups were treated with antibiotic, enrofloxacin. In Group-B withdrawal period was followed and treatment was stopped before 7 days of sacrifice. On the other hand, withdrawal period was not maintained in indiscriminate group and antibiotic treatment was continued until the day of sacrifice. Body weight was recorded daily in the morning. On $31^{\text {st }}$ day mean body weight was highest in Group-C $(1901.17 \pm 15.22 \mathrm{gm})$ and lowest body weight was in Group-A $(1453.33 \pm 26.39 \mathrm{gm})$. The differences among mean weight gain were statistically significant $(\mathrm{P}<0.005)$ in both discriminate \& indiscriminate group compared to control group. Test results found in TLC showed that in discriminate antibiotic group (Group-B) 50\% liver samples, 33.33\% kidney and $16.67 \%$ fat samples were enrofloxacin positive. No sample of thigh muscle, breast muscle and spleen was positive. In indiscriminate antibiotic group (group-C) all the samples were positive in case of liver, kidney, fat and spleen samples. Only $33.33 \%$ and $16.67 \%$ samples were positive in case of fat and thigh muscle samples. All the samples of control group (Group-A) were negative. Overall, the present study documented the widespread abuse of enrofloxacin and failure to implement the recommended withdrawal period will undeniably leads to deposition of residues in broiler tissues.
\end{abstract}

Keywords: antibiotic residue; enrofloxacin; broiler; TLC

\section{Introduction}

Antibiotics are antimicrobial substance which are used against bacterial infections (Geidam et al., 2009). A large number of antibiotics are used in poultry industry (Simon and Baxter, 2006). Antibiotics are used to increase growth rates, feed efficiency, egg production, or to reduce the incidence of diseases in poultry (Dipeolu and Alonge, 2002; Donoghue, 2003). Antibiotics have been used for several decades against bacterial infections, as growth promoters and in prophylaxis (Geidam et al., 2009; Olatoye and Ehinwomo, 2009; Nisha, 2006). Antibiotics have been made it possible for efficient production through proper use of antibiotics, allowing the consumer getting meat and eggs of poultry at reasonable price (Nisha, 2006). In Bangladesh, a large population of poultry farming is done by the so called backyard poultry farmers who readily have access to veterinary drugs and always purchase drugs over the counter for administration without veterinary prescription and supervision. Due to indiscriminate use of antibiotics without maintaining proper withdrawal period, large number of antibiotic residues are deposited in edible poultry tissues and other food animal products (Olatoye and 
Ehinwomo, 2009; Shareef et al., 2009). Veterinary drug residues in poultry meat and eggs may be produced by exposing chickens to drugs or contaminants.

Several screening methods are available for detecting the presence of antibiotics residues in poultry tissues or other food animals (Simon and Baxter, 2006; Shareef et al., 2009; Tajik and Shohreh, 2006). The simplest one, TLC was used in this study for detecting antibiotic residues.

\section{Methods and Materials}

\subsection{Ethical approval of laboratory animals}

The experimental broilers were used ethically and at the end of the experiment sacrificed humanely following the ethical and welfare guidelines set by the Animal Welfare and Experimental Ethics Committee of Bangladesh Agricultural University [approval 5 number: AWEEC/ BAU/2021(09)].

\subsection{Experimental design}

18 apparently healthy day-old "Cobb-500" broiler chicks were purchased from CP Hatchery Ltd, Valuka, Mymensingh. . On the $16^{\text {th }}$ days of age chicks were randomly divided into three groups (Group A, B \& C). Each group contains 6 birds. The birds of Group-A, B and C were kept in different cages. Group A was kept as untreated control \& received non-medicated water. Groups B \& C were administered with enrofloxacin at recommended therapeutic dose $@ 10 \mathrm{mg} / \mathrm{Kg}$, through drinking water. After 7 days, at the age of day 23; antibiotic supply was stopped in the group-B and withdrawal period was maintained. In group-C the antibiotic supply was continued until the day of scarifice. Birds received their freshly prepared daily medication in the morning hour of each day. The concentration of enrofloxacin in the water to give the required dose per kilogram of body weight was calculated by determining the water consumption and body weight of each bird on the day of medication.

\subsection{Sample Collection}

At the end of the experiment six birds from each group were sacrificed ethically. Liver, kidney, breast muscle, thigh muscle, fat and spleen samples were collected. Immediately after collection of sample, these were washed individually several times in physiological saline to remove clotted blood and debris. All samples were marked separately and preserved at $-20^{\circ} \mathrm{C}$ in polythene zipper bags for their extraction and analysis.

\subsection{Sample Preparation}

The samples were stored in the deep freeze at $-20^{\circ} \mathrm{C}$ until further advanced procedures were performed. Samples were grinded with a mortar \& pastel properly. These samples were taken into properly cleaned and sterilized petridishes with proper care. From this $4 \mathrm{~g}$ of sample was taken into beaker with the help of electric balance and spatula. The homogenization was done with the addition of $10 \mathrm{ml}$ phosphate buffer (pH-7.2). After proper mixing, protein contents of these samples were precipitated with the addition of $2 \mathrm{ml}$ trichloroacetic acid (30\%) maintaining sufficient care and attention. Then these samples were taken into properly cleaned and sterilized centrifuge tubes for centrifugation. The centrifugation was performed @ $60000 \mathrm{rpm}$ for 20 min with the help of automatically time regulated centrifuge machine. Then the supernatant was collected in a new tube. The supernatant was extracted with an equal volume of diethyl ether to perform de-fatation. Then mixture was kept for 10 min to become into a separate layer. Then these mixtures were separated from each other, and upper oily layer was discarded but only the bottom layer was collected. This extraction of supernatant was repeated twice with diethyl ether. Then, the extracts were collected into screw cap vial with proper care and kept into refrigerator for further advanced analysis. Total procedure was performed as the reference cited by Poppelka $e t$ al., 2005.

\subsection{Thin layer chromatography (TLC) \\ 2.5.1. TLC apparatus}

TLC plate (MN-Germany), TLC tank and UV detection box (UV light: F18W-Germany) were used. TLC was performed according to Tajick and Shohreh, 2006; Islam et al., 2021; Ali et al., 2020; Das et al., 2020 with some required adjustments. TLC plate was cut into appropriate size $(4 \times 5 \mathrm{~cm})$ from $20 \times 20 \mathrm{~cm}$. A straight line was drawn across the plate approximately $2 \mathrm{~cm}$ from the bottom by a pencil. Another straight line was drawn across the plate below $1 \mathrm{~cm}$ from the upper edge of the plate. Desired spots marking were marked on the bottom line where analytes were dropped. Spots were applied to the plate using thin capillary glass pipettes. A volume of $50 \mu \mathrm{l}$ was used for spotting. Plate was placed in TLC tank (contained mobile phase; Butanol: distilled water: acetic acid $=60: 20: 20$ ) and covered by lid and it was left until the mobile phase reached the upper line. Spots 
were visualized in UV detection box at $256 \mathrm{~nm}$. Spots marking were done by pencil for calculation of retention factor (Rf).

\subsubsection{Calculation of $\mathrm{Rf}$ values}

These measurements are the distance travelled by the solvent, and the distance travelled by individual sample spots. Same Rf value of standard and sample considered similar compound.

\subsection{Data analysis}

Experimental data were introduced and stored in Microsoft Excel-2010 and results were analyzed.

\section{Results}

\subsection{Growth promoting effects of enrofloxacin on broilers at different age}

Antibiotics for the therapeutic and preventive purpose may enhance the body weight gain of broiler by killing bacteria from the body. In this experiment from 16th day onwards, everyday body weight was recorded for each bird up to $31^{\text {st }}$ day (Table 1 and Figures 1, 2, 3, 4). This Experiment showed that, at the beginning of the enrofloxacin antibiotic supply with drinking water, the body weight among the Group A, B \& C did not show any significant differences. However, from day $21^{\text {st }}$ to the end of experiment the results showed that highest body weight found in indiscriminate group of broiler and relatively lowest body weight found in control group of broiler. On day $21^{\text {th }}, 26^{\text {th }}$ and day $31^{\text {st }}$, the body weight of Group-A \& Group-B showed the significant difference $(\mathrm{P}<0.05)$ compared with the body weight of Group-A. On day $21^{\text {th }}, 26^{\text {th }}$ there was no significant difference between Group-B \& Group-C. On the other hand, between group A and C, and group A and B, significant differences were observed. On day $31^{\text {st }}$, there was significant difference among Group- A and GroupB \& Group-C. The use of enrofloxacin antibiotics in poultry as growth promoter have demonstrated beneficial. However, the occurrence of antibiotic resistant bacteria has resulted in the ban of use of antibiotic. Alternative feed additives may also improve broiler performance.

Table 1. Body weight of broilers at different age.

\begin{tabular}{|c|c|c|c|c|}
\hline Age & $\begin{array}{l}\text { Group of } \\
\text { Broilers }\end{array}$ & $\begin{array}{l}\text { Average weight }(\mathrm{g}) \\
(\text { Mean } \pm \text { SEM) }\end{array}$ & P Value & $\begin{array}{l}\text { Level of } \\
\text { significance }\end{array}$ \\
\hline \multirow{3}{*}{ 16th day } & Group-A & $573.7 \pm 18.33$ & & \\
\hline & Group-B & $571.3 \pm 15.69$ & 0.901 & $\mathrm{~ns}$ \\
\hline & Group-C & $563.5 \pm 15.13$ & & \\
\hline \multirow{3}{*}{ 21th day } & Group-A & $861.6 \pm 16.77$ & & \\
\hline & Group-B & $913.6 \pm 8.48$ & 0.018 & $*$ \\
\hline & Group-C & $920.3 \pm 16.77$ & & \\
\hline \multirow{3}{*}{ 26th day } & Group-A & $1154 \pm 18.68$ & & \\
\hline & Group-B & $913.6 \pm 8.48$ & $<0.01$ & $* *$ \\
\hline & Group-C & $1395.17 \pm 14.99$ & & \\
\hline \multirow{3}{*}{31 th day } & Group-A & $1453.33 \pm 26.39$ & & \\
\hline & Group-B & $1777 \pm 12.87$ & $<0.01$ & $* *$ \\
\hline & Group-C & $1901.17 \pm 15.22$ & & \\
\hline
\end{tabular}




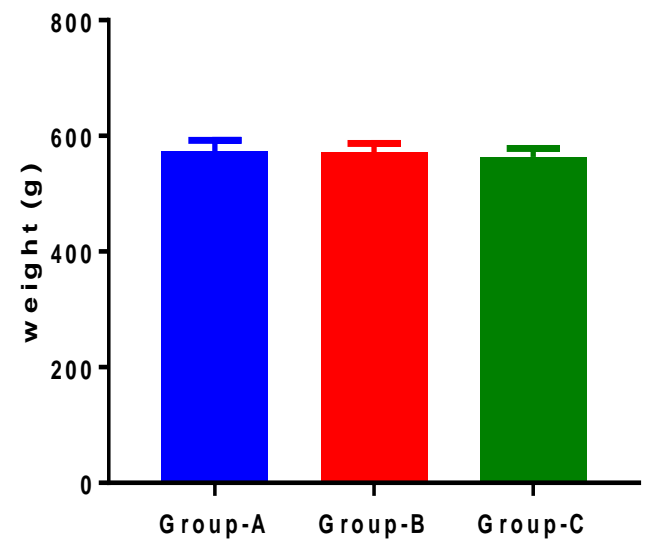

Figure 1. Body weight on $16^{\text {th }}$ day.

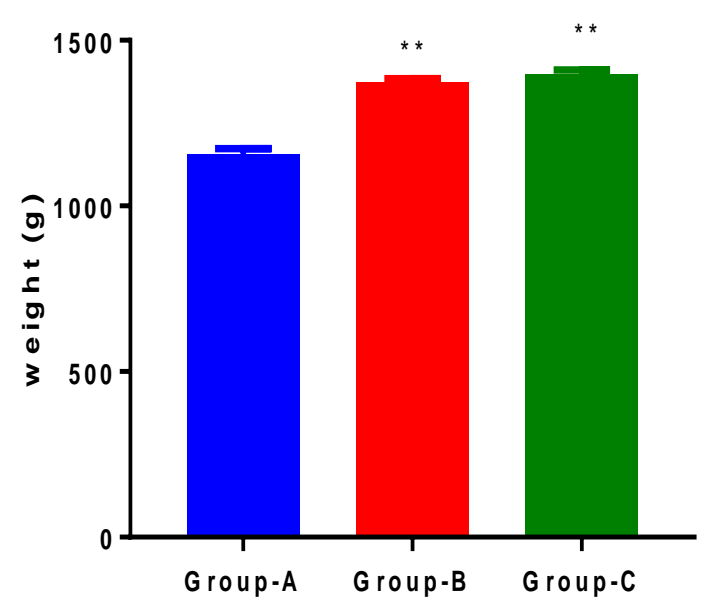

Figure 3. Body weight on $26^{\text {th }}$ day.

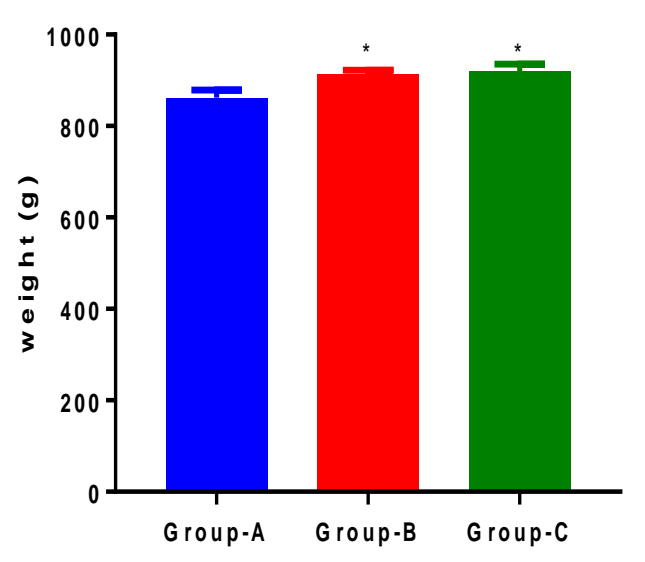

Figure 2. Body weight on $21^{\text {th }}$ day.

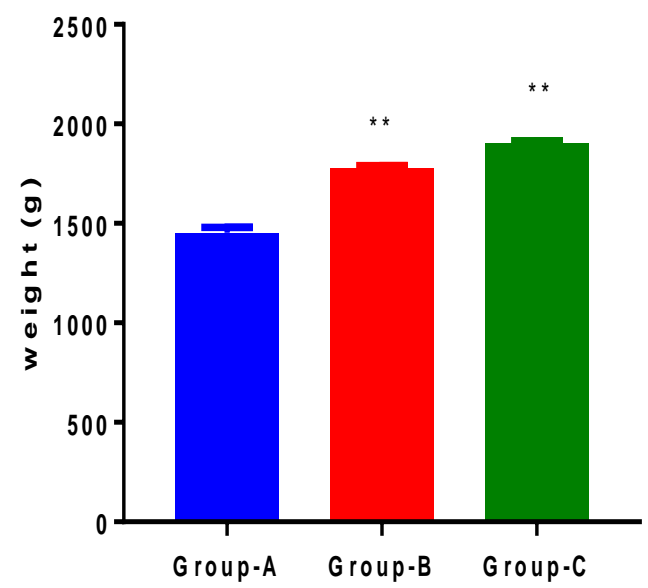

Figure 4. Body weight on $31^{\text {st }}$ day.

\subsection{Enrofloxacin residues in different samples of broiler}

The main goal of this indoor study is to detect the enrofloxacin residue in broiler meat and other edible tissues. The indoor study revealed that, in discriminate antibiotic group (Group-B) 50\% liver samples, 33.33\% kidney, $16.67 \%$ fat and $16.67 \%$ spleen samples were positive. No sample of thigh muscle \& breast muscle were positive. Overall results in the discriminate antibiotic group showed that, among in the total of 36 samples, $16.67 \%$ (6) samples were positive (Table 2 and Figure 5). In indiscriminate antibiotic group (group-C) all the samples were positive in case of liver, kidney, breast muscle and spleen samples. Only $33.33 \%$ and $16.67 \%$ samples were positive in case of fat and thigh muscle samples. A total of $91.67 \%$ (33) samples were positive in that group (Table 3 and Figure 6). All the samples of control group (Group-A) were negative (Table 4 and Figure 7). Overall percentage of positive samples was $54.17 \%$ (39) among all the samples (Both discriminate \& indiscriminate group) (Table 5 and Figure 8).

Table 2. Enrofloxacin residue in different samples of Group-B (Discriminate antibiotic group).

\begin{tabular}{|l|l|l|l|l|l|}
\hline Name of & Total No. of & \multicolumn{2}{|c|}{ No. of sample } & \multicolumn{2}{c|}{ \% of sample } \\
\cline { 3 - 6 } Sample & Sample & Positive & Negative & Positive (\%) & Negative (\%) \\
\hline Liver & 6 & 3 & 3 & 50 & 50 \\
\hline Kidney & 6 & 2 & 4 & 33.33 & 66.67 \\
\hline Thigh muscle & 6 & 0 & 6 & 0.00 & 100 \\
\hline Breast muscle & 6 & 0 & 6 & 0.00 & 100 \\
\hline Fat & 6 & 1 & 5 & 16.67 & 83.33 \\
\hline Spleen & 6 & 0 & 6 & 0.00 & 100 \\
\hline Total & 36 & 6 & 30 & 16.67 & 83.33 \\
\hline
\end{tabular}




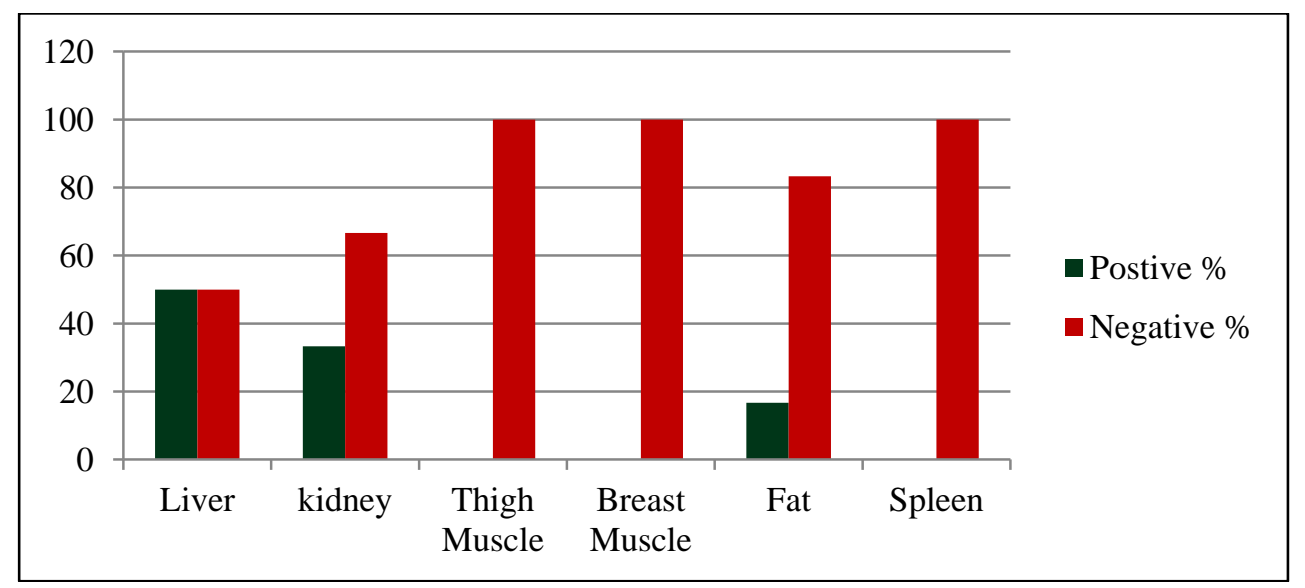

Figure 5. Percentage of enrofloxacin residues in different samples of Group-B (Discriminate group).

Table 3. Enrofloxacin residue in different samples of Group-C (Indiscriminate antibiotic group).

\begin{tabular}{|l|l|l|l|l|l|}
\hline \multirow{2}{*}{$\begin{array}{l}\text { Name of } \\
\text { Sample }\end{array}$} & Total No. of & \multicolumn{2}{|c|}{ No. of sample } & \multicolumn{2}{c|}{ \% of sample } \\
\cline { 3 - 6 } & Sample & Positive & Negative & Positive (\%) & Negative (\%) \\
\hline Liver & 6 & 6 & 0 & 100 & 0.00 \\
\hline Kidney & 6 & 6 & 0 & 100 & 0.00 \\
\hline Thigh muscle & 6 & 5 & 1 & 83.33 & 16.67 \\
\hline Breast muscle & 6 & 6 & 0 & 100 & 0.00 \\
\hline Fat & 6 & 4 & 2 & 66.67 & 33.33 \\
\hline Spleen & 6 & 6 & 0 & 100 & 0.00 \\
\hline Total & 36 & 33 & 3 & 91.67 & 8.33 \\
\hline
\end{tabular}

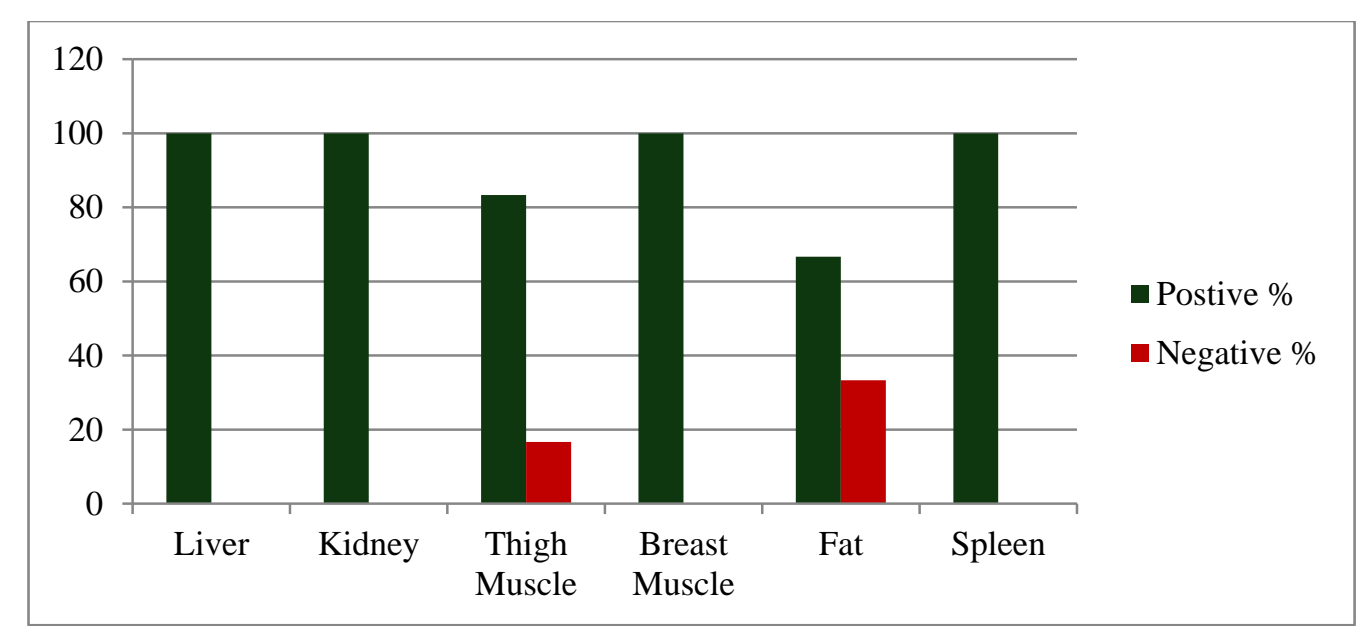

Figure 6. Percentage of enrofloxacin residues in different samples of group-C (Indiscriminate group).

Table 4. Enrofloxacin residue in different samples of group-A (Control antibiotic group).

\begin{tabular}{|l|l|l|l|l|l|}
\hline \multirow{2}{*}{$\begin{array}{l}\text { Name of } \\
\text { Sample }\end{array}$} & Total No. of & \multicolumn{2}{|c|}{ No. of sample } & \multicolumn{2}{c|}{ \% of sample } \\
\cline { 3 - 6 } & Sample & Positive & Negative & Positive (\%) & Negative (\%) \\
\hline Liver & 6 & 0 & 6 & 0.00 & 100 \\
\hline Kidney & 6 & 0 & 6 & 0.00 & 100 \\
\hline Thigh muscle & 6 & 0 & 6 & 0.00 & 100 \\
\hline Breast muscle & 6 & 0 & 6 & 0.00 & 100 \\
\hline Fat & 6 & 0 & 6 & 0.00 & 100 \\
\hline Spleen & 6 & 0 & 6 & 0.00 & 100 \\
\hline Total & 36 & 0 & 36 & 0.00 & 100 \\
\hline
\end{tabular}




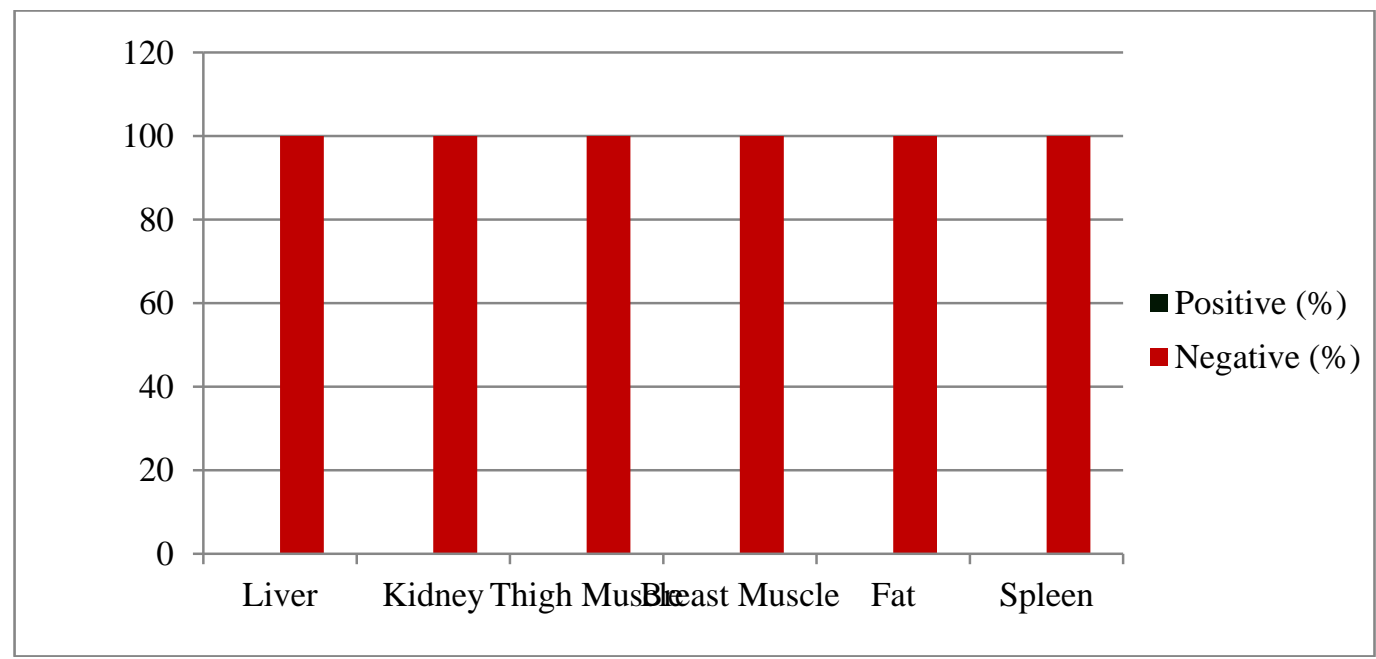

Figure 7. Percentage of enrofloxacin residues in different samples of group-A (Control group).

Table 5. Over all percentage (\%) of Enrofloxacin residue in different samples of broiler.

\begin{tabular}{|l|l|l|l|l|l|}
\hline Name of & Total No. of & \multicolumn{2}{|c|}{ No. of sample } & \multicolumn{2}{c|}{ \% of sample } \\
\cline { 3 - 6 } Sample & Sample & Positive & Negative & Positive (\%) & Negative (\%) \\
\hline Liver & 12 & 9 & 3 & 75 & 25 \\
\hline Kidney & 12 & 8 & 4 & 66.67 & 33.33 \\
\hline Thigh muscle & 12 & 5 & 7 & 41.67 & 58.33 \\
\hline Breast muscle & 12 & 6 & 6 & 50 & 50 \\
\hline Fat & 12 & 5 & 7 & 41.67 & 58.33 \\
\hline Spleen & 12 & 6 & 6 & 50 & 50 \\
\hline Total & 72 & 39 & 33 & 54.17 & 45.83 \\
\hline
\end{tabular}

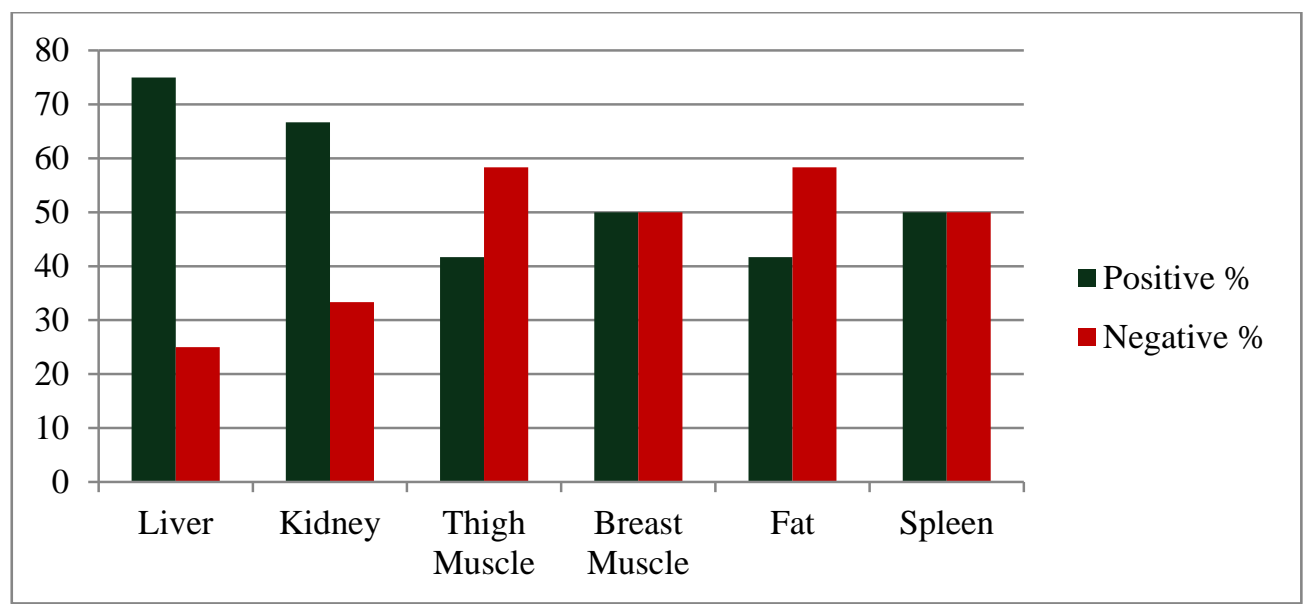

Figure 8. Over all percentage of enrofloxacin residue in different samples of broiler.

\section{Discussion}

As an alternative source of red meat (beef and mutton) poultry meets a large number of our demand (Mehtabuddin et al., 2012). Bangladesh is a developing country which largely depends on the use of poultry meat as a dietary animal protein source. The poultry industry has to face various diseases. Antibiotics are used in the treatment and prevention of these diseases as well as a growth promoter. The presence of antibiotic residues in poultry meat has received attention from public health agencies throughout the world. This is due to the antimicrobial resistance (Yorke and Froc, 2000). Without maintaining proper withdrawal period and nonjudicious use of antibiotics into animal leads to deposition of antibiotic residues into the animal end products. These residues ultimately pose serious health threats to human beings when meat from such animals is consumed (Shareef et al., 2009). Furthermore, these residues may also be formed if proper withdrawal times of 
drugs have not been established. These residues produce a large number of health effects in humans on consumption of contaminated meat (Kožárová et al., 2004). The enrofloxacin has a wide spectrum of activity and being widely used as veterinary drug to improve health conditions. It has good absorption and high bioavailability with good penetration into body tissues and found at high concentrations in the excretory organs, especially the liver and kidney.

In present study, in discriminate antibiotic group (Group-B) 50\% liver samples, 33.33\% kidney, 16.67\% breast muscle, $16.67 \%$ fat and $33.33 \%$ spleen samples were having residues of enrofloxacin. In indiscriminate antibiotic group (group-C) all the samples were positive in case of liver, kidney, fat and spleen samples. Only $33.33 \%$ and $16.67 \%$ samples were positive in case of thigh muscle and breast muscle samples. Among all the 72 samples, $42(58.33 \%)$ samples were positive. Results of this study are also confirmed by Horstkotter et al., 2002 with similar findings. The concentrations of antibiotic residues were more in the liver sample than muscles because enrofloxacin is mainly metabolized in liver. Our results were also consistent with other studies (Sultan, 2014) regarding the highest enrofloxacin residues in poultry liver samples than meat. This may be because enrofloxacin is easily distributed from plasma into tissues (Sultan, 2014). According to Petrovic et al. the level of residues is 2-4 levels greater in the liver than the muscles after treatment with enrofloxacin. Enrofloxacin occurrence in edible tissues and offal were identified through TLC method. Previous studies coincide with the present study which reveals that drug residues above MRL are a serious matter and there is a need of extensive work to quantify residues in the food producing animals particularly poultry.

\section{Conclusions}

Fluoroquinolones constitute an expanding group of synthetic antibiotics, widely used in the treatment of infections in both human and veterinary medicine. A number of these drugs have been licensed to be administered in broiler chickens for the prophylaxis and treatment of respiratory, renal and digestive infections in different regions of the world. Fluoroquinolones are one of the few classes of antimicrobial agents with activity against the full range of pathogens involved in broiler chickens, such as Campylobacter jejuni, Salmonella, Shigella or Escherichia coli, being commonly used. Currently, the widespread use of these antimicrobials such as enrofloxacin in the poultry industry has become a matter of concern because it has led to the emergence of resistance in Salmonella serovars, Campylobacter spp. and E. coli .This situation raises public health concerns regarding reduction in the clinical efficacy of fluoroquinolones in human medicine. In addition, the use of fluoroquinolones in food-producing animals may leave drug residues in foods. These residues represent a risk to public health, including stimulation of bacterial resistance, alterations on intestinal micro flora and hypersensitivity reactions. Extra label use of these drugs or unintentional contamination of feed for poultry (cross-contamination during premix manufacture or during feed transport) may be the source of violative drug residues in meat for human consumption. Therefore, the depletion of these drugs in meat and other edible tissues should be assessed. Considering the above-mentioned issues and the fact that published information regarding enrofloxacin depletion in poultry meat and offal is scarce (Lolo et al., 2006) the present study was designed. Administration of enrofloxacin was started at 16 days of age and continued for $31^{\text {st }}$ days of age. Mean body weight was highest for indiscriminate group. The mean differences among the three groups were statistically significant $(<0.05)$.

The TLC was performed for identification of antibiotic residues. The analysis revealed that all the samples were positive in indiscriminate group with an exception of fat tissue (66.7\%). There was no positive sample in control group. The results indicate the presence of residues, whereas the usage of this contaminated meat causes resistance in consumers and seems to be a public health threat. Thus, there is a need to educate the farmers about the ill effects of residual drugs on human health and withdrawal time in poultry birds. National authorities should also adopt more judicious approaches to ensure prudent use of antibiotics in food animals.

\section{Acknowledgments}

This work was supported by the Ministry of Science and Technology, Government of the People's Republic of Bangladesh by a grant in research, Ref. No. 39.00.0000.009.14.011.20-59/BS-21.

\section{Conflict of interest}

None to declare. 


\section{References}

Ali MR, MMH Sikder, MS Islam and MS Islam, 2020. Investigation of discriminate and indiscriminate use of doxycycline in broiler: an indoor research on antibiotic doxycycline residue study in edible poultry tissue. Asian J. Med. Biol. Res., 6: 1-7.

Das D, MS Islam, MMH Sikder, F Alom, MA Sharmin and MZF Ashraf, 2020. Presence of antibiotic residue and residual effect of tylosin tartrate in broiler. Int. J. Nat. Soc. Sci., 7: 29-35.

Dipeolu MA and DO Alonge, 2002. Residues of Streptomycin antibiotic in meat sold for human consumption in some states of SW Nigeria. Archivos de Zootecnia, 51: 447-480.

Donoghue DJ, 2003 Antibiotic residues in poultry tissues and eggs: Human health concerns? Poult. Sci., 82: 618-621.

Geidam, YA, MHI Usman, F Anosike and Y Adeyemi, 2009. Oxytetracycline and procaine penicillin residues in tissues of slaughtered cattle in Maiduguri, Bornostate, Nigeria. Terrestrial and Aquatic Environmental Toxicology, 3: 68-70.

Horstkötter C, E Jiménez-Lozano, D Barron, J Barbosa and G Blaschke, 2002. Determination of residues of enrofloxacin and its metabolite ciprofloxacin in chicken muscle by capillary electrophoresis using laserinduced fluorescence detection. Electrophoresis, 23: 3078-3083.

Islam MS, MR Hasan and MS Islam, 2021. Thin layer chromatographic investigation of antibiotics residues in edible poultry tissues in Bangladesh. World Journal of Biology Pharmacy and Health Sciences, 5: 24-32.

Kožárová I, DM Mate and KT Hussein, 2004 High-performance liquid chromatographic determination of sulfadimidine residues in eggs. Acta Veterinaria, 54: 5-6.

Lolo M, S Pedreira, JM Miranda, BI Vazquez, CM Franco, A Cepeda and C Afente, 2006. Effect of cooking on enrofloxacin residues in chicken tissue. Food. Addit. Contam, 23: 88-93.

Mehtabuddin AA, MT Ahamad, S Nadeem, ZI Tanveer and J Arshad, 2012. Sulfonamide residues determination in commercial poultry meat and eggs. Journal of Animal and Plant Sciences, 22: 473-478.

Nisha AR, 2008. Antibiotic residues: A global health hazard. Vet. World, 1: 375-377.

Olatoye IO and AA Ehinwomo, 2009. Oxytetracycline residues in edible tissues of cattle slaughtered in Akure, Nigeria. International Journal of Food Safety, 11: 62-66.

Petrović JM, B Milan and V Cupic, 2006. Residues of enrofloxacin and its main metabolite ciprofloxacin in broiler chickens. Acta Veterinaria, 56: 5-6.

Popelka P, J Nagy, R Germuška, S Marcinčák, P Jevinova and AD Rijk, 2005. Comparison of various assays used for detection of beta-lactam antibiotics in poultry meat. Food Additives and Contaminants, 22: 557-562.

Shareef AM, ZT Jamel and KM Yonis, 2009. Detection of antibiotic residues in stored poultry products. Iraq Journal of Veterinary Science, 23: 45-48.

Simon AH and GA Baxter, 2006. Biosensor screening for veterinary drug residues in food stuffs. Journal of AOAC International, 89: 862-867.

Sultan IA, 2014. Detection of enrofloxacin residue in livers of livestock animals obtained from a slaughterhouse in Mosul City. J. Veterinar. Sci. Technolo., 5: 2.

Tajik MA and B Shohreh, 2006. Detection of antibiotics residues in chicken meat using TLC. Int. J. Poult. Sci., 5: 611-612.

Yorke JC and P Froc, 2000. Quantification of nine quinolones in chicken tissues by HPLC with fluorescence detection. Journal of Chromatography A, 882: 63-67. 